Article

\title{
Designing the Learning Experiences in Serious Games: The Overt and the Subtle-The Virtual Clinic Learning Environment
}

\author{
Joshua G. Peery ${ }^{1, *(1)}$ and Celen Pasalar ${ }^{2}$ \\ 1 College of Nursing, East Carolina University, Greenville, NC 27858, USA \\ 2 College of Design, North Carolina State University, Raleigh, NC 27695, USA; celen_pasalar@ncsu.edu \\ * Correspondence: peeryj15@ecu.edu; Tel.: +1-919-395-2304
}

Received: 24 May 2018; Accepted: 26 June 2018; Published: 29 June 2018

\begin{abstract}
Serious Games are becoming more common in the educational setting and must pass muster with both students and instructors for their learning experience and knowledge building. The Virtual Clinic Learning Environment has recently been developed and implemented at East Carolina University using a design framework based on Bloom's variables, and in the process of refining those design questions, identifies the methods of how serious games provide an overt and subtle learning experience. The overt learning experience is based in the design questions defined and the subtle experience was derived by examining the idea of sense of place as it relates to the virtual environment. By considering these two streams of learning, designers can avoid pitfalls and build on these design elements of a virtual learning environment.
\end{abstract}

Keywords: serious games; nursing education; virtual environments; game design; instructional design

\section{Introduction}

The changing nature of the field of nursing and increasing need on expanding capacity to meet the rising demand for health care requires an advanced curriculum that can educate students on developing skills in critical thinking, leadership, case management, health promotion, and the ability to practice across a variety of inpatient and outpatient settings [1,2]. The National Advisory Council on Nurse Education and Practice (NACNEP) found that registered nurses additionally should be well skilled with problem solving, communication, and have the ability to analyze and communicate data [2]. Commonly used instructional strategies typically include "the use of standardized patients, actors, peers, faculty or manikins for students to practice techniques and receive feedback, which require significant institutional resources including faculty time and physical space" [3] (p. 1). In the search for innovative health care training, the Virtual Clinic Learning Environment (VCLE) was recently developed and housed at East Carolina University's College of Nursing. The use of VCLE has provided a fertile test bed in which implements a Serious Game into the various courses and curricula in the University's Division of Health Sciences. The enterprise started with in-house developers and subject matter experts and then grew to include video game industry veterans and external development teams, along with pedagogy experts in the field of health sciences. Interdisciplinary collaboration in developing such training systems is essential in order to achieve an efficient and impactful product, as suggested by Anton et al. [4].

Following the implementation of the ideas, observations, and development methods outlined in Peery's 'Questions for Serious Game Development for Success', and with the addition of new viewpoints and experiences, this paper seeks to add to the resources that educators and serious game designers have available [5]. This effort aims to help build the perceived value of serious games 
through sharing the VCLE's narrative of an on-going project. The further examination in how serious games function in education continues to build the gravitas of serious games as an educational method that is accepted by educators at differing levels and is equally well-received by the students, both as a useful learning tool and as a positive experience [6]. The growth of successful serious games is two-pronged: instructors need to be comfortable in utilizing such tools as educational methods and the students must also have a positive learning experience.

In line with these aims, this paper further discusses Bloom's 'Learning for Mastery, Instruction and Curriculum' and its variables, along with the design questions proposed by Peery [5,7]. With this context in mind, serious games are conceptualized by demonstrating how they can be developed and designed to successfully adopt the idea of using a 'game' in courses. The concepts of overt learning experience and sense of place in virtual environments are then explored as theoretical foundations through critical discussion of existing approaches. Considering all the derived information, the further development of the VCLE and observations of its implementation is explained as an example, followed by suggestions for new areas to adapt the application of serious games in learning experiences.

\section{Virtual Clinic Learning Environment (VCLE) Framework}

\subsection{Attributes of Serious Games and Instructional Design}

Aptitude, quality of instruction, ability to understand instruction, perseverance, and time allowed for learning are important parts of the mainstream understanding of educational methods and features for instructional design as outlined by Benjamin Bloom [7]. As a traditional, pen-and-paper classroom teacher would take these aspects into account, so must the serious game designer, as explained by Peery [5]. Within the framework of Bloom, aptitude relates to a set of users (i.e., students) in mind and the learning outcomes for the serious game. Quality of instruction relates to vetting the subject matter experts that provide the required educational content [5]. Similarly, it is important that the user is able to understand the content delivered through the serious game. Hence, the user interface (UI)/user experience (UX) must be evaluated and designed with the users in mind. In addition, the ability to use and re-play serious games remotely and asynchronously allows for easier perseverance and flexibility in time [5].

As further extrapolations of Bloom's variables, a serious game designer must also address the following key questions about the game and instructional experience they are creating as outlined by Peery [5,7]:

- Does learning feel like play?

- Are the experiences interconnected?

- Does the player learn by doing?

- Is failure reframed as iteration?

- Is feedback immediate and ongoing?

- Is the challenge constant and consistent?

These two sets of ideas from Bloom and Peery provide both the serious game designer and instructor with a solid set of "rules" by which to design a serious game, but what about the actual modes of learning and experiences that the student is encountering when presented with this video game/digital medium? Most work on serious games focus on specific aspects of serious games in terms of domains of training, as well as methods and results [8]. However, none describe the game's design and playability with respect to learning and experiences [8]. Therefore, the VCLE is introduced using the framework proposed by Peery [5].

\subsection{VCLE Conceptual Description}

A major challenge in health education is to provide the clinical training opportunities. These experiences are necessary to the students' development of clinical critical thinking skills. The VCLE 
is an online, browser-based virtual reality trainer that East Carolina University (ECU) faculty and staff developed to allow students to learn via virtual cases designed by instructors. The application is a web-based, asynchronous, immersive clinic environment into which nursing students enter to meet and interact with instructor designed virtual patients and preceptor avatars. The instructor builds each case via a web application. Once the cases are created, the game engine allows students to walk through a virtual space that has been made to resemble a community clinic based on an existing, real-world setting, and to interact with the virtual patient that utilizes text-to-speech to respond. In the VCLE, with preceptor feedback and guidance, students interview patients using a classic diagnostic sequence to arrive at a diagnosis and care plan for each patient.

The VCLE is composed of three functional parts, including the clinic environment (the student side), the Casebuilder (the instructor side), and administration tools. Instructors use the Casebuilder to create cases targeting a specific health issue, which is then presented, as a patient, to students through the VCLE framework. The sequenced steps of the Casebuilder correspond to the steps in a classic medical diagnostic sequence. These steps are: patient demographics, vital signs, health history, chief complaint, history of present illness (HPI), review of systems, physical exam, lab tests, differential diagnosis, and request for interprofessional consult, diagnosis, and care plan. If a section is not needed for a case, instructors can select "No" next to the "Show this step to students" feature. Sections can also be re-ordered at the instructor's discretion. In addition, the Casebuilder features a built-in survey tool that requires students' input to complete the case.

The sections of the Casebuilder act as a guide to the instructor by providing all the elements required to design a complete patient case. Using the Casebuilder's sections and patient record form as a structure, the tool allows the instructor to create a complete patient case easily, without any programming or game design knowledge. The instructor can also populate the patient, preceptor, and clinic receptionist avatars (3-D models) for their individual cases in the VCLE via drop-down menus in the Casebuilder.

Students work through the VCLE cases at their own pace. In each section featured in a case, the student is presented with a set of questions created by instructors from which he or she chooses the ones that are appropriate or correct to be asked. The patient avatars answer each question and students gather information throughout the stepwise sequence in this manner, just as they would while working on a real-life case. Students are then scored on their selection at the end of each case section. They are evaluated on whether they choose all the correct questions that need to be asked or whether they choose to ask questions that were inappropriate, incorrect, or non-applicable. The student's success at formulating a correct diagnosis and care plan for each patient/case is based on their ability to gather and interpret the correct and most pertinent information.

The VCLE supports multimedia and can play/display audio, image, and movie files. This enables the instructor to upload supporting information, such as images of physical conditions (i.e., skin lesions, X-rays, ultrasounds etc.), audio files (i.e., heart sounds, breathing, etc.), and video files. There is an integral text editor with which the students keep their case notes that instructors also evaluate. Using the Casebuilder, instructors are able to write dialogue for the patients and preceptors, which is converted to sound files by the text-to-speech (TTS) engine. Patients and preceptors audibly speak their answers and feedback to students. Students have described this feature as an essential element in enhancing the realism of the clinic experience. The TTS also supports multiple languages.

The web-based nature of the VCLE makes it an excellent resource for both distance education (DE) programs and training for practicing in other cultures and regions. Due to its asynchronistic nature, DE students are able to play the cases for their courses when convenient for their schedules. A further benefit is that while traditional clinical training is limited to a specific location with patients and pathologies typical to that local environment, the VCLE allows instructors to ignore physical practice boundaries and present students with patients and pathologies from anywhere in the world. This facilitates the ability to present students with culturally and ethnically diverse patients and patient cases expressing conditions endemic to a specific environment. Also, with instructor driven content, 
the VCLE can focus on specific fields of study with increased granularity. For example, the VCLE was recently utilized in a multi-million-dollar grant to increase geriatric treatment awareness across medical disciplines featuring multiple geriatric cases that were custom designed for the effort.

\subsection{VCLE Technical Overview}

There are two major operational application components to the VCLE, the front end (graphical clinic interface) and the back end (database and code). Virtual Clinic uses Unity3D, which is a cross platform gaming engine supporting WebGL (browser-based gaming). When a student runs a case, data created in the web application is passed to the WebGL-based game. Once launched, the game then uses the data to set up the gaming scenario. Student/patient interactions are scored within the game and then the results are passed back to the web application.

The front-end component communicates with the back-end via web service API methods, which are exercised by the VCLE back-end web framework. The back-end consists of two major parts: (1) a central database in Microsoft SQL Server 2008, and (2) a website that integrates both front and back ends. The database stores all the configuration information for cases, course, case assignments, students' grade histories, and account information. For security considerations, the database is maintained behind a firewall.

\section{Serious Game as Adjustable Learning Scaffold and the Overt Learning Experience}

There is growing research that looks at information-communication technologies aiming to improve learning efficiency using tools, such as virtual laboratories, which mainly focus on strengthening academic content and learning experiences (e.g., teaching social interactions and emotions to individuals with autism spectrum disorders) [8,9]. Various research using virtual and augmented reality tools have also been linked to the activities of the manufacturing industry (e.g., welding), and other practices, such as training activities in military, sports, and medical fields [9-11].

Many medical, nursing, physical therapy, and pharmacy programs have been using Virtual Patient Simulations (VPS) in practice-based courses, enabling students to conduct patient exams in a stimulating, convenient, and realistic way [3]. For example, the Shadow Health Digital Clinical Experience (DCE), as a web-based virtual patient simulation, has been used to provide students with the opportunity to interview, examine, document, and reflect on their experiences, while interacting with standardized patients. These "overt learning experiences" not only introduce the students to technical aspects of physical assessment but also involve them in interviews that motivate further patient engagement [3].

The idea of the "overt learning experience" that a serious game imparts is part of the "nuts and bolts" of knowledge acquisition, as outlined by Bloom and Peery [5,7]. The Virtual Clinic Learning Environment was first developed for graduate and Doctorate of Nursing Practice student coursework. However, the game has recently gone through an iterative design and polishing process that utilized the input gained from the consulting video game designers, as well as a serious game pedagogy expert. Through that process, the system was given some new features. In addition, some insights were gained on the possibility to create learner-scaled Virtual Clinic cases for use by undergraduate students that were deemed feasible. This exploration in adapting the VCLE to deliver a different learning experience led to this observation of how the serious game "works" to instruct in an "overt" manner.

Part of the solution to making the overt learning experience adjustable is the new feature where the question sections in the VCLE cases can have their order arranged and/or selected for use. For example, undergraduate students may not need sections on procedure codes or diagnosis, thus those sections can be left out of the case presented to the students, all while adjusting the learning scaffold to areas that are appropriate to their knowledge level.

To further develop content for undergraduate students, the following excerpt from Dr. Dickey's Virtual Clinic Learning Environment report on the system's merit and pedagogy was considered [12]: 
"Introductory Student Case: In introductory cases, students could watch or shadow a master practitioner. Students would not only watch the processes, but also have access to the internal processes. This could be achieved with a character who is the master practitioner. The diagnostic process would also include the master practitioner explaining internal reasoning for gathering and analyzing data in the diagnostic process."

To put the "Introductory Student Case" concept into practice, a solution was designed where the avatar of the Preceptor/Instructor would be added to the exam room as the "companion" to the patient. This role is usually only used to represent a family member, guardian, or caregiver. Section questions were written that "ask" the preceptor/instructor what the appropriate course of action in the given situation should be expected. This option is always prompted to the students to choose as a correct action ahead of time. This "question" always preceded the students' choices in the "testing" section.

For example, this is how a Chief Complaint section could work:

1. CConsult Instructor> What should we do first? "Ask your patient an open-ended question."

2. How are you today, what can I help you with? "I'm having trouble swallowing."

3. What do you want? "My throat hurts. Is there a problem?"

In the above example questions 1 and 2 would be correct to ask, with option 3 being too terse and rude. This is an example of the players learning by doing after having structured guidance. For the questions in the interview section, the designer should consider providing good-better-best options. Specifically, the questions considered for patients and how they are being communicated in a manner that is more appropriate when interacting with a patient are important (e.g., greetings and asking for reasons for the visit) [13]. Furthermore, the following should be taken into consideration:

- The case should be meaningful and present the problem clearly.

- The distractors/alternatives should be plausible and should be homogenous.

- All options should be of similar lengths.

- The use of negative questions should be avoided.

- Embedding clues to the correct response within the question choices and the responses should be avoided.

- Wrong answers need to be in a proportionate number to the correct answers.

Rather than merely stating a response is wrong or incorrect, learners should be provided with a detailed supportive statement about why a response was wrong or right. Time and attention to filling in the "rationale" fields in the Virtual Clinic's Casebuilder is considered a major priority as per the idea that feedback should be immediate and ongoing in serious games.

Case section selection is also an important step. There is often the impulse (nature abhors a void) to use and fill in every question section available in the Virtual Clinic. The idea of "less is more" should at least be in mind when designing a case to meet a learning objective. This gain through subtraction is part of the idea and implementation of interconnected experiences. If a case is focused on obtaining information on the Chief Complaint or History of Present Illness sections, then it may behoove the case designer to leave off sections dealing with ordering labs or identifying procedure codes.

A case should also include an opportunity to reflect. It can be helpful to ask a student how they experienced the case. The new built-in survey section of the Virtual Clinic can provide this opportunity with an open-ended question and any number of 1-5 scaled questions.

The secondary benefit of using the built-in survey section is to obtain data on the overall effectiveness of the case and the Virtual Clinic as a learning tool. Coupled with comprehensive feedback available in the final scores and students' Subjective, Objective, Assessment, and Plan (SOAP) Notes, it is possible to generate information about areas of weaknesses and strengths. This is useful in helping to identify knowledge gaps and develop an understanding of the students' metacognitive processes over the long run. These further aid in adjusting the learning scaffold and the "overt" learning experience. This delivery of knowledge and content is the "overt" learning experience that subject matter experts, instructors, and serious game designers strive to impart. 


\section{Sense of Place from the Virtual: The Subtle Learning Experience}

A facet of the Virtual Clinic Learning Environment that can be overlooked when designing similar serious games, while delivering an "overt" learning experience, is the importance of the sense of place where activities and interactions with patients are taking place. This concept is based in the idea that a virtual environment can deliver more than the technical knowledge that is being imparted. A serious game can be designed to have any sort of user experience (UX) and user interface (UI) that the creators can imagine or implement. The virtual space itself is a powerful part of the learning experience that carries many qualities of the real world [14]. Hence, the instructor is not constrained to teaching the information inside a traditional classroom.

Relph states that "sense of place" enables us to understand and appreciate the distinctive characteristics of places [14]. Those characteristics of a place shape our everyday experiences and activities by evoking our feelings, senses, and emotions [14-16]. Hence, the design of a physical environment and its atmosphere can provide effects on learning outcomes and stimulate active learning $[16,17]$.

Previous research has demonstrated how space configurations can motivate and influence the knowledge creation, communication, and application, particularly in regular educational settings $[18,19]$. In a similar sense, virtual learning environments, if designed as reproductions of real environments, can provide context for an activity and dynamic interactions to occur with the content delivered $[8,16,20,21]$. However, Grossard et al. reveal that most serious games allow for working on only a few specific situations, and functional generalization of behavior, which may not be efficient, as social rules change with environmental context [8].

Serious games are regarded as goal-directed learning activities rather than being just for fun and enjoyment [22-24]. Arora et al. also assert that "the design of learning spaces in virtual environments needs to be influenced by the learners' understanding of a place associated with learning activities" [16] (p. 4). It should provide sufficient characteristics of the real settings that learners are used to in a real environment. The nature of these environments conveys a message about the atmosphere of these environments through our senses and sets expectations regarding how these spaces will be used in terms of the knowledge and content provided [16].

In a recent study, Anton et al. present a novel telecollaboration system for remote consultation that uses artificial reality (AR) and virtual reality (VR) to connect a remote instructor and a worker. Through this work, they compare the interaction and communication between the two users when using three different communication interfaces in terms of performance, speed, workload, and user experience. In particular, 3-D technology was considered as a favorable and innovative approach to interaction by providing a more detailed view of the environment for real-time visualization [25].

Part of the design considerations for the virtual space and how it enhances the sense of place is how the realistic idea of moving through the space is balanced against UX and UI issues that must be addressed in all video games, but even more so in serious games. An early version of the VCLE featured the student/user having direct control over their movement through the virtual space. This freedom was determined to be a detriment to the experience and the ability for the game to provide a focused learning experience. Players would spend too much time navigating the virtual space or be too unfamiliar with navigating an avatar through a virtual space and give up from frustration. The design decision was made to place the players' viewpoint "on rails," meaning the player controls when to move from point-to-point, but with no control of the movement itself. This was deemed more acceptable and has been the movement feature going forward. When the issue was revisited during the recent upgrades to the VCLE, the idea of simply teleporting the player from point-to-point was deemed too immersion breaking and detracted from the idea of being in "real" clinic. Sense of place mattered in this decision.

The VCLE in that sense acts as an inviting place to which students spend quality time performing meaningful activities and interacting with the content and knowledge disseminated via avatars and cases built as serious games. With the notion of sense of place being an important part of the game's 
design and the instructional experience, the question of "Does the game's environment enhance the learning experience?" becomes the seventh question to add to the framework proposed by Peery, where applicable [5].

\section{Methods}

\subsection{Deploying the Virtual Clinic Learning Environment to a New Audience}

The ongoing mission statement of the Virtual Clinic Learning Environment is to create a low-risk environment for students to practice critical thinking and problem solving, allow students with disparate schedules and locations to learn online at their own pace, present content designed to reflect patients that students may not otherwise encounter, allow the students to experience the space of a clinic, and be able to create highly reusable content that can be used with international audiences to expand global health opportunities.

To help fulfill this mission, the virtual environment/place was designed to impart the sense of place as detailed above. The players entered the virtual space through glass double doors (Figure 1) and approached a receptionist avatar who is positioned behind a large desk that would likely be found in the real setting (Figure 2). The player then walked through the halls of the clinic to a well-appointed office where the player was given an overview of the case by a preceptor avatar (Figure 3). The player then moved through the clinic's hallways to their own computer station where they sat at a virtual computer and reviewed the case file (Figure 4). Once complete, the player would be moved through the clinic's halls to one of several exam rooms that features different accoutrements depending on the case's designer's needs (Figure 5). If the player required an external consultation they would move through the halls to a conference room featuring a large television monitor to interact with other virtual entities as needed or designed (Figure 6). Once the player had concluded their cases, they would return to the preceptor's office to experience the case's conclusion.

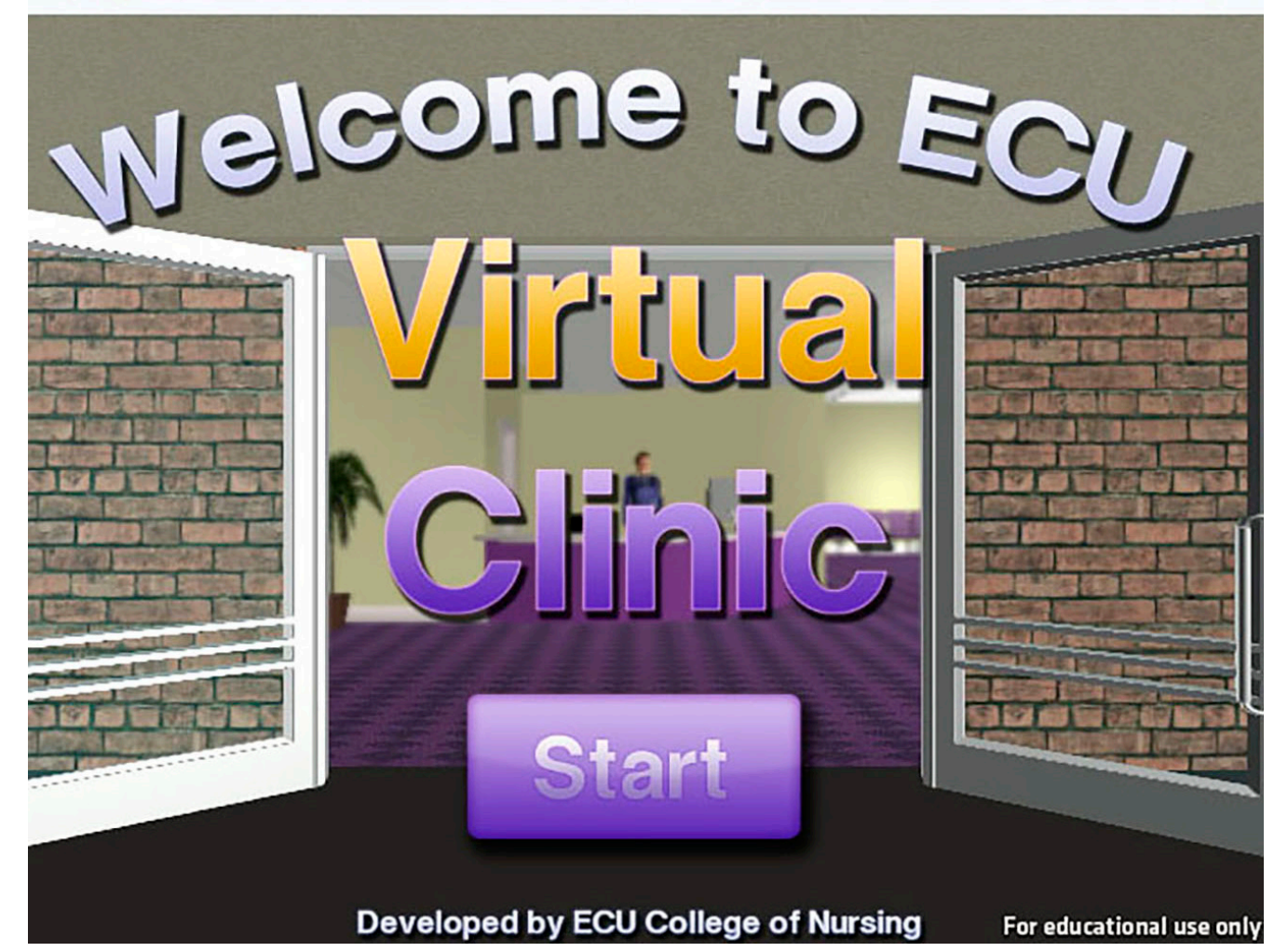

Figure 1. The entry experience through the Virtual Clinic. 


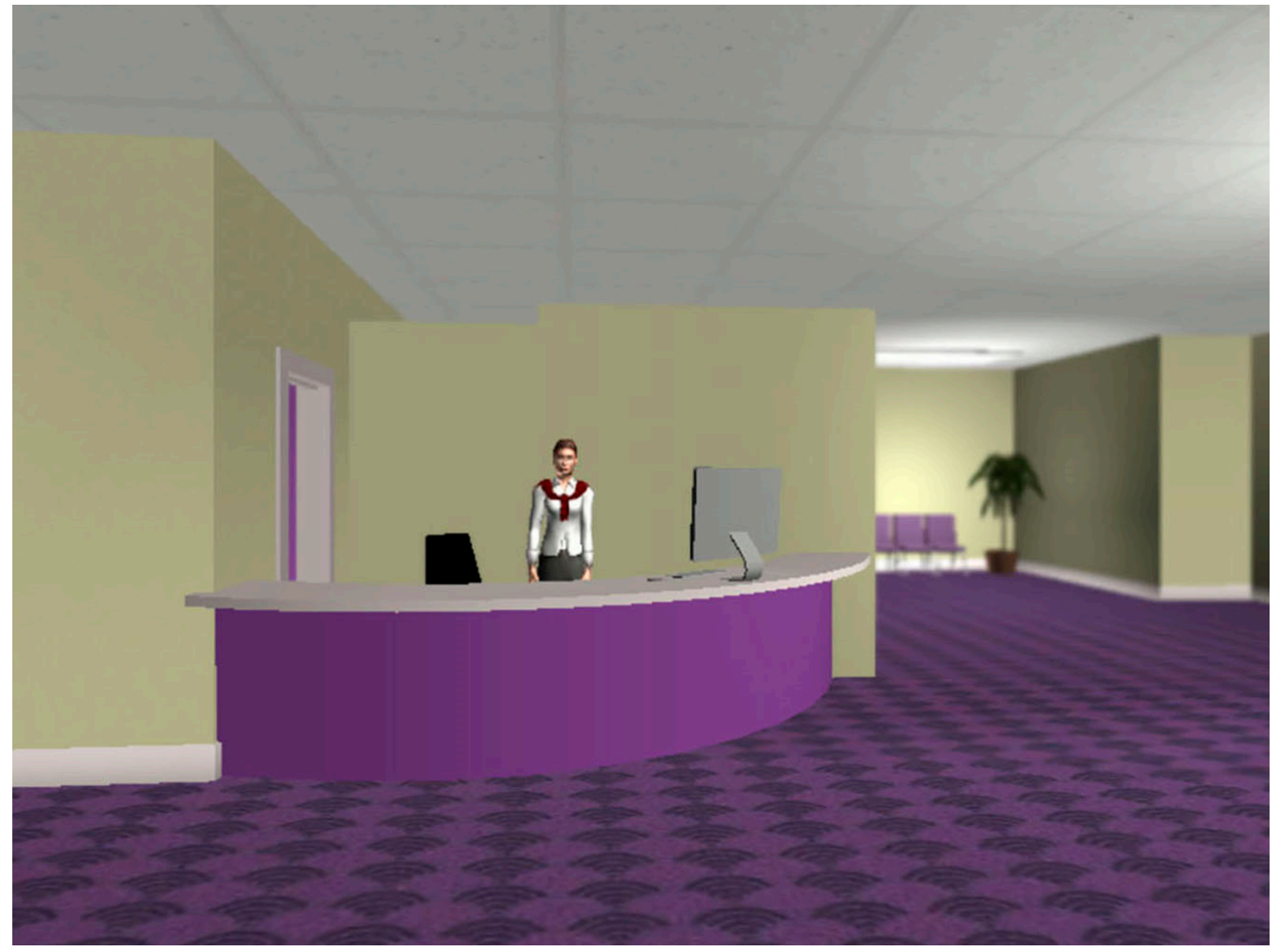

Figure 2. The reception area in the Virtual Clinic.

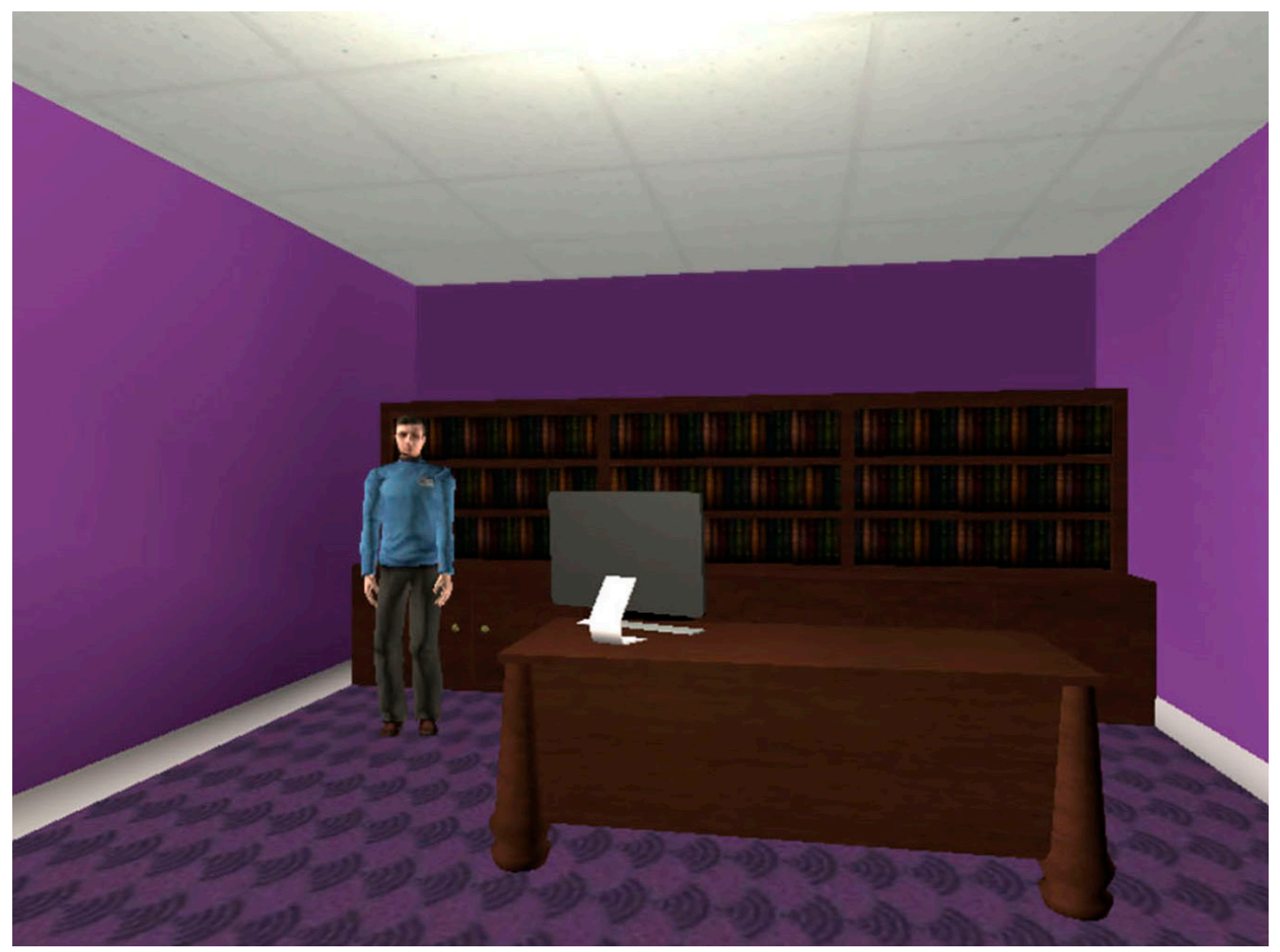

Figure 3. An office space in the Virtual Clinic-meeting with the preceptor. 


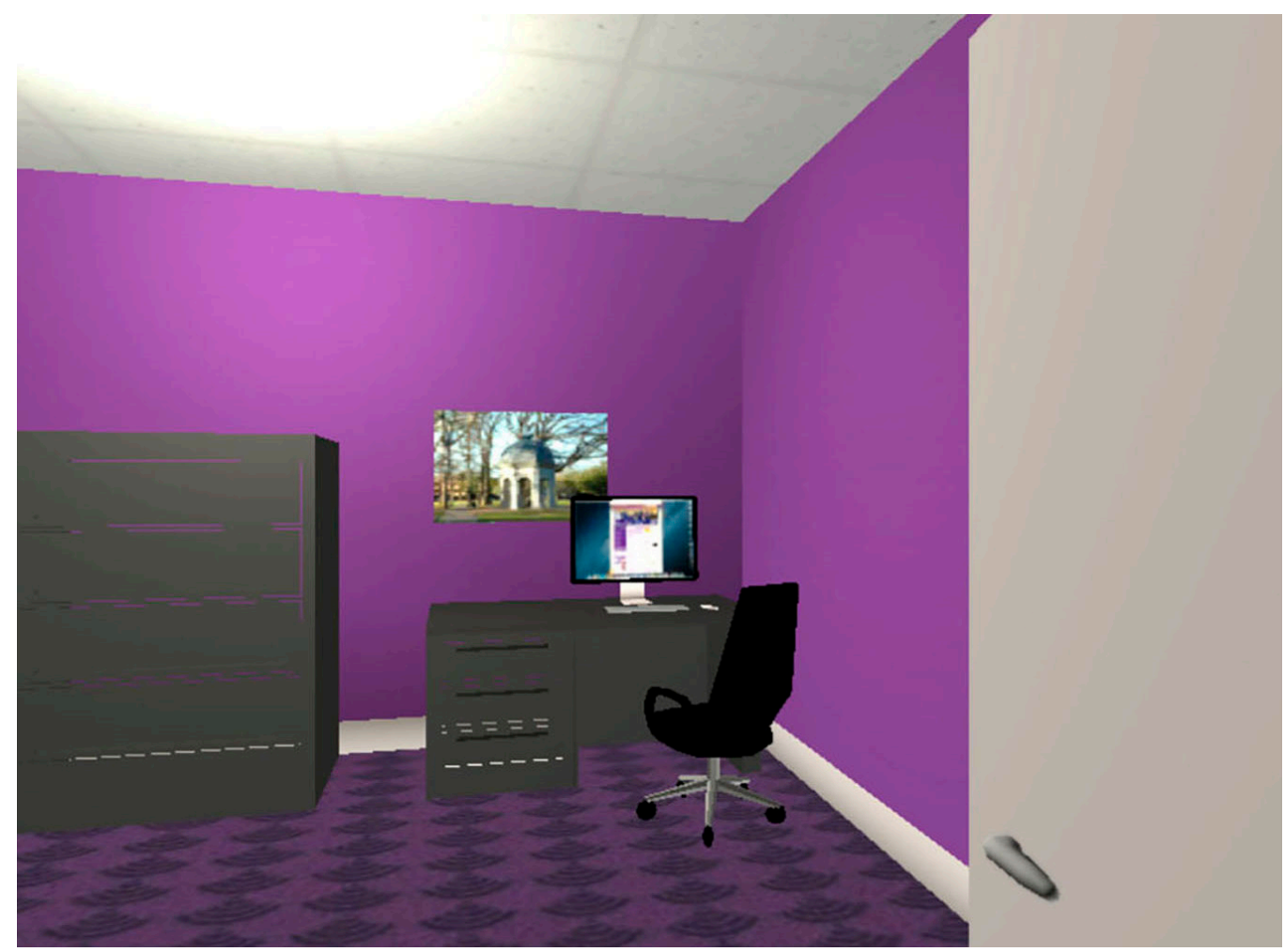

Figure 4. Computer station.

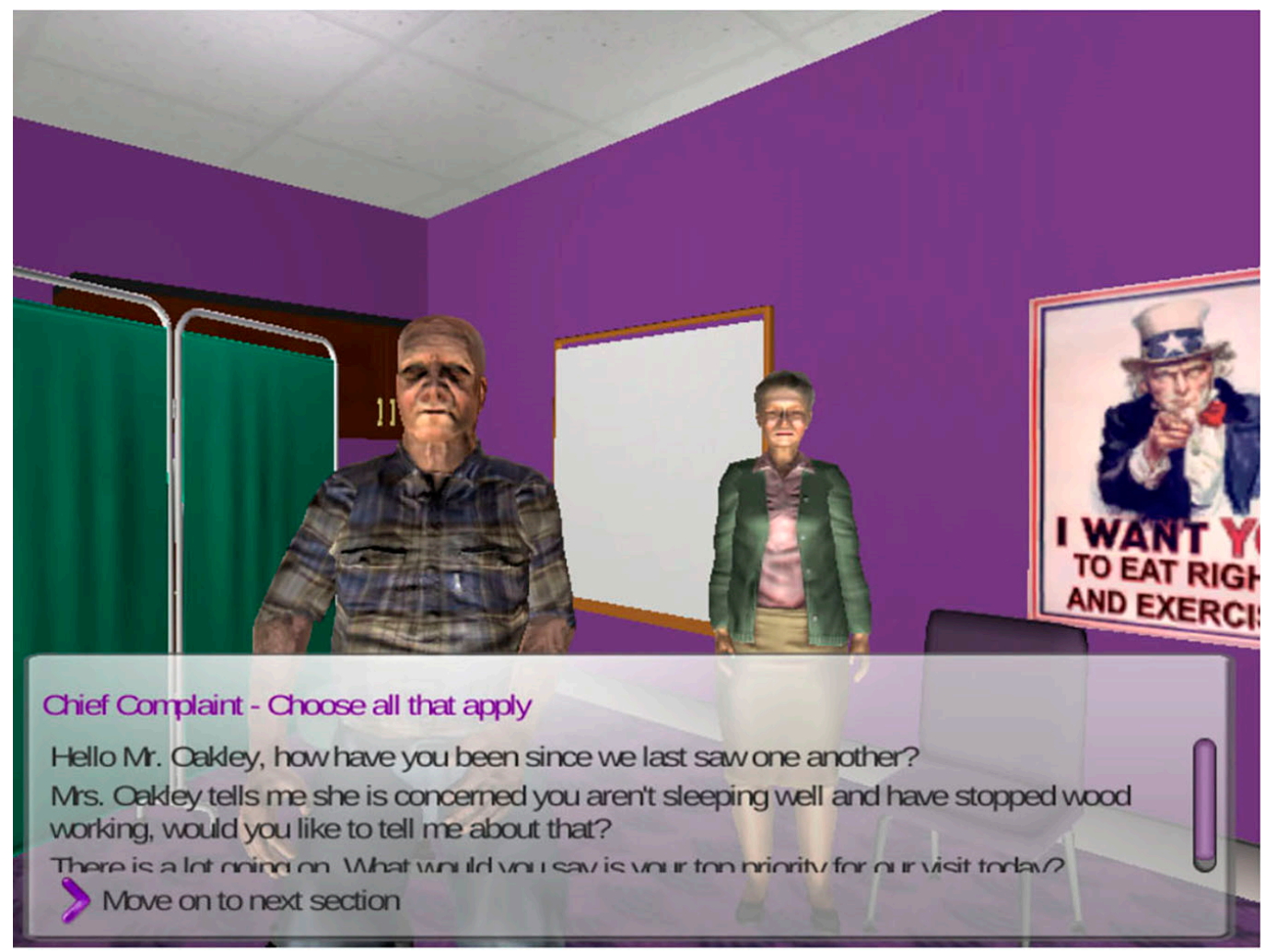

Figure 5. User interface-interacting with a patient in the exam room. 


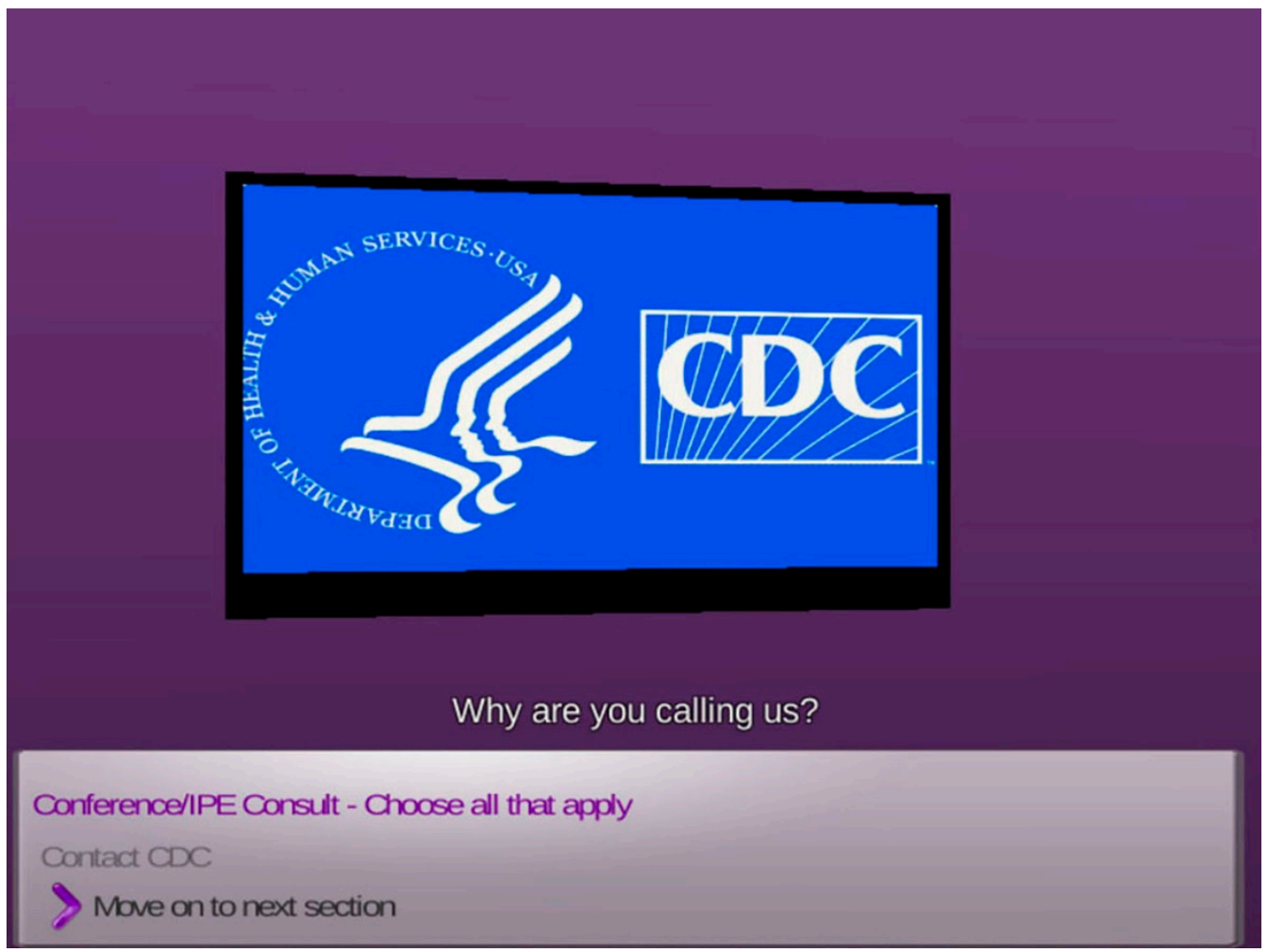

Figure 6. Conference room for external consultation.

During fall 2017, a total of 16 students (3 males and 13 females), mostly representing juniors and a few seniors, participated in a lab-based clinical nursing foundation class, which used Virtual Clinic Learning Environment as part of the instruction. All of the students enrolled in this undergraduate course were in their second semester of the nursing program. Through this course, the participating students had to attend a two-hour mandatory laboratory session that included both the use of VCLE and a traditional manikin simultaneously. Within the framework of this course, the VCLE was used for conducting the pre-operation interviews with the patients in a virtual clinic environment, while the manikins were used to engage students in more hands-on pre-operation tasks in a simulated hospital room.

In adapting and piloting the VCLE to undergraduate studies, the case design and its knowledge framework had to be adjusted by engaging the faculty in the process as well. The time to experience the case had to fit within a class schedule as students were expected to complete the case while in class. With the reduction in scope of the knowledge scaffold, the average time to complete the case fit the timeframe of the students' lab session, with half of the students working with a traditional manikin, while the other half worked in the VCLE before switching activities. Similarly, the students were asked to use any resource available to them (e.g., textbooks, online resources, etc.) while working through the material covered in the VCLE case.

\subsection{User Experience Survey}

As part of the second version of the VCLE, a brief built-in survey tool was also piloted where open-ended feedback and data from Likert scale questions were collected from the students as a required step but with no bearing on their grades. This Likert scale questionnaire was based on a 5 -point scale ( $1=$ strongly disagree, $2=$ disagree, $3=$ neutral, $4=$ agree, $5=$ strongly agree). This was an important part of collecting information on how the users feel about the content and their experiences in using the VCLE in order to inform whether the readjusted learning scaffold was 
effective. Students were asked seven questions regarding their experiences in utilizing the VCLE, their interaction with cases/knowledge presented, feedback received, as well as their willingness to use it again in the future. These statements were extracted and adapted from the simulation survey that students were asked to evaluate the Simulation Lab coursework as required for the accreditation of Nursing Simulation Labs. An open-ended question was also included in this questionnaire in order to allow for additional student comments.

The Virtual Clinic was presented to students with no prior experience with the VCLE. Students were informed about the use of the VCLE and the survey at the beginning of the lab session. They were also made aware that the case and the VCLE system were being adapted and used with undergraduate students for the first time.

\section{Results and Discussions}

The clinical training opportunities are necessary to the students' development of critical thinking skills in health sciences. The VCLE offers cases that allow students to walk through a virtual space resembling an existing community clinic and interact with the virtual patient that utilizes text-to-speech to respond. The goal is for students to effectively communicate and engage with patients using a classic diagnostic sequence and come up with a patient care plan as future practicing nurses.

Within the framework of this paper, the use of the VCLE was evaluated in a single course with a small sample size, so the results may not be generalized at this point. It is also important to note that the long-term impact of student performance with and without the use of the VCLE is beyond the scope of this paper. In addition, it does not aim to compare VCLE with other available systems from the point of user perceptions. Instead this paper focuses on revealing the process of how the VCLE was developed and adapted to undergraduate courses, while understanding students' preliminary opinions on using the VCLE system.

The values shown in Table 1 are the first results from the piloted survey presenting the percentage distribution. There was strong agreement on all the survey items, with the lowest agreement rate on question \#4 with $68 \%$ agreeing or strongly agreeing that the simulation was designed for their specific knowledge and skill level. There were three questions with very low level of disagreement or neutral responses. These items included questions \#3, \#5, and \#7. Based on these results, $88 \%$ of participating students thought that the cues provided in the VCLE cases were appropriate to promote students' understanding. $100 \%$ of participating students also agreed that the feedback provided through the cases was constructive. In addition, $87 \%$ of students indicated that they would like to use the Virtual Clinic in the future.

Table 1. The Likert scale questions used to understand how the users feel about the content and their experience in using the VCLE. Responses to Survey Items $(\mathrm{N}=16)$.

\begin{tabular}{|c|c|c|c|c|c|c|}
\hline \multirow[t]{2}{*}{ Survey Question } & \multicolumn{2}{|c|}{$\begin{array}{c}\text { Strongly } \\
\text { Disagree/Disagree/Neutral }\end{array}$} & \multicolumn{2}{|c|}{ Agree } & \multicolumn{2}{|c|}{ Strongly Agree } \\
\hline & $\mathbf{n}$ & $\%$ & $\mathbf{n}$ & $\%$ & $\mathbf{n}$ & $\%$ \\
\hline $\begin{array}{l}\text { Q1. There was enough information provided at the } \\
\text { beginning of the simulation to provide direction. }\end{array}$ & 3 & 19 & 11 & 69 & 2 & 12 \\
\hline $\begin{array}{l}\text { Q2. I clearly understood the objectives of the Virtual } \\
\text { Clinic Case. }\end{array}$ & 3 & 19 & 11 & 69 & 2 & 12 \\
\hline $\begin{array}{l}\text { Q3. The cues were appropriate to promote my } \\
\text { understanding. }\end{array}$ & 2 & 12 & 11 & 69 & 3 & 19 \\
\hline $\begin{array}{l}\text { Q4. The simulation was designed for my specific } \\
\text { level of knowledge and skills. }\end{array}$ & 5 & 31 & 6 & 37 & 5 & 31 \\
\hline Q5. Feedback provided was constructive. & 0 & 0 & 9 & 56 & 7 & 44 \\
\hline Q6. The scenario resembled a real-life situation. & 4 & 25 & 6 & 37 & 6 & 37 \\
\hline Q7. I would like to use the Virtual Clinic in the future. & 2 & 12 & 10 & 62 & 4 & 25 \\
\hline
\end{tabular}


Open-ended comments were also collected and have been edited for grammar and redacted appropriately (see selected comments in Table 2). Gathering comments through open-ended questions seemed to make student experience measurements more informative and student-centered. The responses by students were well-received by both the instructors and the VCLE designers. In particular, the unasked-for comparisons to another software and students' overall satisfaction and experience with the VCLE were interesting. Each student feedback that referenced the other commercially available software was referring to the same product.

Table 2. Selected comments from the students on their experiences in using the VCLE.

\begin{tabular}{l}
\hline "The program is good, I liked the options, they are realistic responses." \\
"Good learning example overall. It could come in handy over time especially to new nursing students that have never \\
done any one-on-one care. The fact that it doesn't take long is good as well." \\
"I really enjoyed this activity. Being able to look up the answers as I did the activity helped me to concrete the \\
information in my brain and really understand what I was learning." \\
"I think it was a good learning experience. It reminds me of <commercially available software>, something we did in \\
Health Assessment, last semester. It really puts things into a more realistic perspective." \\
"This was a different experience that helped me look up information that was needed to help treat patients." \\
\hline "I really enjoyed having multiple choice answers. Also, I liked the realistic feel of being able to interview the patient." \\
\hline "I do not usually like virtual learning because the scenarios are really scripted and do not usually respond \\
appropriately. This was not bad. I would like to see what other situations can be put in place." \\
"This was much better than <commercially available software>." \\
\hline "The simulation is harder to start compared to <commercially available software>, however it moved through much \\
faster and was more user friendly than <commercially available software>. \\
"This was an interesting learning experience, a lot like our <commercially available software>, but I liked this better. \\
It was a lot less confusing than <commercially available software>, which made it more enjoyable." \\
"I like this virtual clinical experience. I like that it gave you immediate feedback and let you know if the answers you \\
put down were right or wrong. The virtual clinical experience was much easier to use and follow along." \\
\hline
\end{tabular}

The pilot survey results revealed promising findings regarding VCLE as an educational tool. Likert scale and open-ended student responses from the survey validated the initial goals that the VCLE aimed to achieve. Students indicated that VCLE was overall a positive learning experience, even for those who were not involved and experienced in one-on-one care before. The tool enabled students to put things into a more realistic perspective by being able to interview the patient in an actual virtual setting resembling an existing clinic space. The easy interface and well-crafted scripts were also appreciated and considered to be user friendly. Moreover, students highly appreciated the immediate feedback received on their responses to questions.

\section{Conclusions and Next Steps}

In this paper, we have laid out how using the conceptual foundations of the Bloom's variables and Peery's design questions are informing us on how to develop and design serious games that successfully adopt the idea of using a game in courses and adapt their learning scaffolds to different levels of students. Using the theoretical frameworks of learning experiences and sense of place, the paper explained how the Virtual Clinic Learning Environment (VCLE) continues to develop and put into implementation achieving objectives on critical thinking and problem solving in the areas of health sciences and patient treatment.

In utilizing the VCLE as an enterprise level instructional tool, this paper revealed the design of the serious game, and by extension, the questions that the designer used to guide the development process. The data collection from stakeholders and student surveys further added to this body of information by outlining additional questions informing the designer's design thinking process. Refining the survey instruments to measure the students' perceived sense of place besides learning and how they feel about the content and their experiences in using the VCLE will be important in the future. Being able to show 
meaningful results and feedback beyond the student scores from a larger sample will be invaluable to this process as we continue to refine the VCLE as a viable tool to experience the space of a clinic, while encountering unique patient cases and health matters. Future studies can also aim to compare VCLE with other available systems from the point of user perceptions using the piloted questionnaire.

Finally, exploration of porting the VCLE to Virtual Reality (VR) headsets can also aid in collecting data on whether VR immersion aids the sense of place in the game, and by extension, how much of an impact or improvement it will have to the student experience and learning.

Author Contributions: Conceptualization: J.P. and C.P.; Formal Analysis: J.P. and C.P.; Writing-Original Draft: J.P. and C.P.; Writing-Review and Editing: C.P.

Funding: This research received no external funding.

Acknowledgments: Cheryl Elhammoumi, RN, MSN-ED, CCRN for her collaboration in using the VCLE in her undergraduate class sections as a pilot case. Mel Swanson for his assistance in data analysis and formatting.

Conflicts of Interest: The authors declare no conflict of interest.

\section{References}

1. Rosseter, R. Fact Sheet: Nursing Shortage. American Association of Colleges of Nursing, the Voice of Academic Nursing, 2017. Available online: http: / / www.aacnnursing.org/Portals /42/News/Factsheets / Nursing-Shortage-Factsheet-2017.pdf (accessed on 17 June 2018).

2. Johnson, J. Differences in the performance of baccalaureate, associate degree and diploma nurses: A meta-analysis. Res. Nurs. Health 1988, 11, 183-197. [CrossRef] [PubMed]

3. Taglieri, C.A.; Crosby, S.J.; Zimmerman, K.; Schneider, T.; Patel, D.K. Evaluation of the Use of a Virtual Patient on Student Competence and Confidence in Performing Simulated Clinic Visits. Am. J. Pharm. Educ. 2017, 81, 87. [PubMed]

4. Anton, D.; Berges, I.; Bermudez, J.; Goni, A.; Illarramendi, A. A Telerehabilitation System for the Selection, Evaluation and Remote Management of Therapies. Sensors 2018, 18, 1459. [CrossRef] [PubMed]

5. Peery, J. Questions for Serious Game Development for Success. In Proceedings of the 2016 IEEE International Conference on Serious Games and Applications for Health (SeGAH), Orlando, FL, USA, 11-13 May 2016; pp. 1-4. Available online: https:/ / www.computer.org/csdl/proceedings/segah/2016/2210/00/07586227abs.html (accessed on 20 May 2018).

6. Smith, M.A.; Mohammad, R.A.; Benedict, N. Use of Virtual Patients in an Advanced Therapeutics Pharmacy Course to Promote Active, Patient-Centered Learning. Am. J. Pharm. Educ. 2014, 78, 125. [CrossRef] [PubMed]

7. Bloom, B.S. Learning for Mastery, Instruction and Curriculum. Eval. Comment 1968, 1, 1-12.

8. Grossard, C.; Grynspan, O.; Serret, S.; Jouen, A.; Bailly, K.; Cohen, D. Serious Games to Teach Social Interactions and Emotions to Individuals with Autism Spectrum Disorders (ASD). Comput. Educ. J. 2017, 113, 195-211. [CrossRef]

9. Torres, F.; Tovar, L.A.N.; del Rio, M.S. A Learning Evaluation for an Immersive Virtual Laboratory for Technical Training Applied into a Welding Workshop. EURASIA J. Math. Sci. Technol. Educ. 2017, 13, 521-532. [CrossRef]

10. White, S.; Prachyabrued, M.; Chambers, T.; Borst, C.W.; Reiners, D. Low-Cost Simulated MIG Welding for Advancement in Technical Training. Virtual Real. 2011, 15, 69-81. [CrossRef]

11. Nee, A.Y.C.; Ong, S.K. Virtual and Augmented Reality Applications in Manufacturing. In Proceedings of the 7th IFAC Conference on Manufacturing Modelling, Management and Control, International Federation of Automatic Control, Saint Petersburg, Russia, 19-21 June 2013; pp. 15-26.

12. Dickey, M. Report: Evaluation of the Virtual Clinic. Unpublished Report to ECU CoN. 2016.

13. Kelley, C.G. Using a Virtual Patient in an Advanced Assessment Course. J. Nurs. Educ. 2015, 54, $228-231$. [CrossRef] [PubMed]

14. Relph, E. Spirit of Place and Sense of Place in Virtual Realities. Technè Res. Philos. Technol. 2007, 10, 17-25. [CrossRef] 
15. Ciolfi, L.; Bannon, L.J. Space, Place and the Design of Technologically Enhanced Physical Environments. In Space, Spatiality and Technology; Turner, P., Davenport, E., Eds.; Springer: Dordrecht, The Netherlands, 2005; pp. 217-232. ISBN 1402032722.

16. Arora, V.; Khazanchi, D. Sense of Place in Virtual World Learning Environments: A Conceptual Exploration. In Proceedings of the Faculty Presentations on Department of Information Systems and Quantitative Analysis, University of Nebraska, Omaha, NE, USA, 21-22 May 2010; Digital Commons@UNO: Omaha, NE, USA, 2010. Available online: http:/ / digitalcommons.unomaha.edu/isqafacproc/8 (accessed on 1 May 2018).

17. Lippincott, J.K. Linking the Information Commons to Learning. In Learning Spaces; Oblinger, D.G., Ed.; Educause: Louisville, CO, USA, 2006; ISBN 0-9672853-7-2.

18. Clark, S.; Maher, M.L. The Effects of a Sense of Place on the Learning Experience in a 3D Virtual World. In Proceedings of the 10th Association for Learning Technologies Conference on Communities of Practice, Sheffield, UK, 8-10 September 2003; Cook, J., McConnell, D., Eds.; pp. 82-101.

19. Peck, M.S. Meditations from the Road; Simon and Schuster: New York, NY, USA, 1993; ISBN 0-671-79799-9.

20. Hirose, M.; Takahashi, K.; Koshizuka, T.; Morinobu, T.; Watanabe, Y. An Alternate Way to Generate Virtual Worlds: A Study of Image Processing Technology for Synthetic Sensations. Presence Teleoper. Virtual Environ. 1996, 5, 61-71. [CrossRef]

21. Dourish, P. Re-Place-ing Space: The Roles of Place and Space in Collaborative Systems. In Proceedings of the 20th Anniversary Conference on Computer Supported Cooperative Work, Banff, AB, Canada, 4-8 November 2006; ACM: New York, NY, USA, 2006; pp. 299-308.

22. Huizinga, J. Homo Ludens: A Study of the Play Element in Culture; Beacon Press: Boston, MA, USA, 1955; ISBN 978-1-62138-999-6.

23. Caillois, R. Man, Play, and Games; Free Press: New York, NY, USA, 1961; ISBN 0-252-07033-X.

24. Iten, N.; Petko, D. Learning with Serious Games: Is Fun Playing the Game a Predictor of Learning Success? Br. J. Educ. Technol. 2016, 47, 151-163. [CrossRef]

25. Anton, D.; Gregorij, K.; Bajcsy, R. User Experience and Interaction Performance in 2D/3D Telecollaboration. Future Gener. Comput. Syst. 2018, 82, 77-88. [CrossRef]

(C) 2018 by the authors. Licensee MDPI, Basel, Switzerland. This article is an open access article distributed under the terms and conditions of the Creative Commons Attribution (CC BY) license (http:/ / creativecommons.org/licenses/by/4.0/). 